\title{
Assessment of training effectiveness: review article
}

\begin{abstract}
An effective training makes an employee more efficient and productive. It is crucial for enhancing the skills, capabilities and knowledge of the employee. The value of the training lies in what it achieves. Assessment of training effectiveness is an essential activity because it examines to what extent the gained knowledge is actually transferred to the workplace. This review was aimed to find out the gap in the existing literature to develop foundation of the new research on assessment of training effectiveness especially on project management related courses. A number of original articles were critically reviewed repeatedly. Some gaps have been found.
\end{abstract}

Keywords: training, effectiveness, assessment, project Management, gained knowledge, business management, learning outcomes, communication, ethics, knowledge, critical thinking, trade instrument
Volume 2 Issue 4 - 2018

\author{
Hasan Tarik \\ National Academy of Planning and Development, Bangladesh
}

Correspondence: Hasan Tarik, Director Research and Publication, National Academy of Planning and Development, Bangladesh, Email cnbuhs20I3@gmail.com

Received: July 25, 2018 | Published: August 03, 2018
Abbreviations: SALG, students assessment learning gains; ALO, academic learning outcome; PM, project management; $\mathrm{CRH}$, collaborative reproductive health; AARDO, afro Asian rural development organization

\section{Introduction}

The aim of providing training is to ensure that an employee is capable of performing better in the current role. Training can be a source of achieving competitive advantage where the gained knowledge and skill of the employee can reap benefit for the organization. Project management training is very much important for a fast growing developing country like Bangladesh, where there is a direct linkage between development and project implementation. Training evaluation is carried out to anticipate the extent of improvement in the trainee's work performance, to authenticate training as a trade instrument, to analyze return on investment, to modify course curriculum and training methods. This review highlights on training effectiveness assessment.

\section{Evaluation of the training effectiveness}

Shariff et al., ${ }^{1}$ conducted a study on 165 business management undergraduates after completion of students' projects in 2011 to assess the project management skills and learning outcomes. The study found that project management skills like teamwork, leadership and problem solving were demonstrated by the students while implementing university projects, academic and students' society projects. After thorough review of this paper, it is found that methodology section of the paper is very concise. Sampling technique is not clearly written. Questionnaire method was followed. Survey was conducted only among the students. Evaluators' feedbacks were not incorporated. Limitation of the study was not included in the article suggests that for evaluating the effect of education five design criteria can be used for an updated Students Assessment Learning Gains (SALG) which includes measurement of satisfaction, using pre and post-tests, identifying ability, account for learning and account for attrition. The tests were conducted through survey questionnaire with the students of a professional master degree program. After critical review of the paper, it was found that the sample size was very small and response rate was not adequate. The result of the test produced ambiguous result. In this paper, it is recommended to conduct further research to assess the added value by identifying the learning gains and capability in pre and post-tests ${ }^{2}$ conducted a study to measure the Project Management (PM) Academic Learning Outcome (ALO) where students are assigned to teams in a business simulation. They ought to measure five important academic learning outcomes (ALO); like content knowledge, critical thinking, communication, ethics and project management by developing a modified Project Management assessment guideline.

It is suggested from the study that a carefully developed assessment guideline can ensure that students are learning powerful tools which lead organizations for better execution of projects. Their effort was to guide the students to identify and rate Project Management team activities effectively. In this paper, research methodology and sampling techniques were not clearly described ${ }^{3}$ examined the utilization of acquired knowledge, skill and attitude of the Bangladeshi participants of the training courses organized by Afro Asian Rural Development Organization (AARDO). The study was based on primary source of data collected from 60 respondents through structured questionnaires. Effectiveness of the programmed was examined with questions on whether the contents of the training were adequate to meet the demand. Benefits and utilization of the learning were assessed by measuring the relevancy of the contents, methods and techniques and the extent of utilization of the skill in the professional field. The study found that relevance level and the levels of knowledge, skill and attitude development were very high. The limitation of this study was found that this result reveals from the participants' self-assessment. Trainers, participants' supervisors and organizers' feedback were not incorporated in the study. The non-trainees' feedback could also be taken to conduct three sixty degree evaluation ${ }^{4}$ conducted a study to explore the influencing factors for skill utilization in enterprise systems. They found that the determination of the application of the skills acquired during training in the Enterprise System based work environment depends on individual and organizational factors. Motivational determinants for individuals in this aspect are computer self-efficacy and mastery orientation. Prior computer knowledge helps the end - users to be confident and able to face challenge in the workplace. Employers' motivation to learn is affected by mastery orientation which is preceded by skill transfer. Organizational factors also act as motivational determinants for training utilization. These factors include top management commitment, IT team support, project champions and support by departmental and supervisory heads.

After critical review of this paper, the limitation was found that there is no information about population and sample size $\mathrm{e}^{5}$ examined an assessment structure designed for a Post-graduate construction project management course to evaluate the learning outcome among 29 Post-graduate students. He found that the students preferred 
research - based group assignments to be effective for learning technical content, for developing teamwork and communication skills. He also suggested formulating mechanism to assess individual contributions to group assignments. The findings of this study also revealed that individual assignment, group work, formative and summative assessments are also important for evaluation. Limitation of this study was found that the study was conducted with a very few number of sample and with a specified group of students ${ }^{6}$ examined the formative assessment technique in the project management course at Holy Family University with the participation of the faculty members in a classroom assessment support group. Three techniques were used for assessment which was directed paraphrasing, student generated test questions and group evaluation. The faculty members' feedbacks were also incorporated. These techniques were found appropriate for the course. The author also recommended using minute paper and muddiest point to evaluate the students. Since these techniques are participatory, those should be included for conducting an effective project management course ${ }^{7}$ conducted a study to evaluate the training and competency building of the ERP end users in the context of an oil and Gas Company. The study suggested a modified approach which supports the end-users to use ERP applications effectively. The authors identified that it is a part of knowledge and change management in managing ERP critical success factors. The modified approach was supported by the iceberg competency model, training management cycle and Kirk-Patrick's evaluation model. The new approach offers flexibility and considered useful for implementing end-users competency building program which ultimately leads to profitability and return on investment.

Table I Reviewed article can be summarized in the following table

\begin{tabular}{|c|c|c|c|}
\hline SL. No. & Reference & Factors identified/used & Methodology \\
\hline \multirow[t]{2}{*}{1} & Shariff ${ }^{10}$ & Demonstration of Project Management & Questionnaire Method \\
\hline & & Skills: Planning, leading, organizing, Coordination and Control (PLOCC) & \\
\hline 2 & Nijhuis $^{7}$ & $\begin{array}{l}\text { Five design criteria for students Assessment Learning Gains including } \\
\text { measurement of satisfaction, using pre and post-tests, identifying ability, account } \\
\text { for learning and account for attrition. }\end{array}$ & Survey Questionnaire \\
\hline 3 & Hornyak $^{6}$ & $\begin{array}{l}\text { Five academic learning outcomes like content knowledge, critical thinking, } \\
\text { communication, ethics and project management }\end{array}$ & Simulation \\
\hline 4 & Begum ${ }^{3}$ & $\begin{array}{l}\text { Relevancy of the contents, methods and techniques and the extent of the } \\
\text { utilization of the skill. }\end{array}$ & $\begin{array}{l}\text { Structured Interview, FGD, } \\
\text { Case Study }\end{array}$ \\
\hline 5 & Arasanmi' & $\begin{array}{l}\text { Computer self-efficiency, mastery orientation, management commitment and } \\
\text { support }\end{array}$ & $\begin{array}{l}\text { Positivist Qualitative } \\
\text { approach, Unstructured } \\
\text { interview }\end{array}$ \\
\hline 6 & Zou $^{12}$ & $\begin{array}{l}\text { Formative and Summative assessment, individual contribution to group } \\
\text { assignment, group work }\end{array}$ & Questionnaire survey \\
\hline 7 & Purcell (n. d.) & $\begin{array}{l}\text { Formative assessment like directed paraphrasing, student generated tests } \\
\text { questions and group evaluation. }\end{array}$ & $\begin{array}{l}\text { Group Work, Teaching, } \\
\text { Feedback }\end{array}$ \\
\hline 8 & $\begin{array}{l}\text { Albadni and } \\
\text { Abdallah }\end{array}$ & End users competency leads to Profitability and return on investment & Case study \\
\hline 9 & Warui"l & Lack of adequate training influences the school management & $\begin{array}{l}\text { Descriptive Survey, } \\
\text { questionnaire, observation } \\
\text { Schedule }\end{array}$ \\
\hline 10 & Rehman $^{9}$ & $\begin{array}{l}\text { Framework to measure training effectiveness, diagnose problems at various } \\
\text { stages of training cycle }\end{array}$ & $\begin{array}{l}\text { Descriptive and exploratory } \\
\text { research methodology, } \\
\text { questionnaire survey }\end{array}$ \\
\hline II & Dumark $^{5}$ & $\begin{array}{l}\text { Prioritization of Project Management Knowledge Area (PMKA) Contributes to } \\
\text { Sustainable outcome. }\end{array}$ & Case Study \\
\hline 12 & Bean $^{4}$ & $\begin{array}{l}\text { Cross-cultural training (CCT) plays an important role for the development } \\
\text { of individual and organizational cultural competence which reinforces social } \\
\text { cohesion and social capital. }\end{array}$ & $\begin{array}{l}\text { Literature review, } \\
\text { consultations, surveys }\end{array}$ \\
\hline
\end{tabular}

The authors suggested for further research for the refinement of the approach ${ }^{8}$ conducted a study to evaluate the impact of training on project management effectiveness among 20 public secondary school principals in Kenya. The study addressed that whether lack of project management training affected successful accomplishment of school management of principals. The findings of this study revealed that training plays an important role in the performance of school management. The principal of a school can be considered as a project manager who needs to plan, implement, manage, maintain and evaluate the entire education system. So it is a prime need for the school principles to be trained in project management ${ }^{9}$ examined the training effectiveness among 115 project directors in project organizations in Pakistan. The authors identified that organizations invest resources on training without analyzing the effectiveness of training interventions in achieving organization's goal and objectives. The study found that training utilization is ineffective and there is a poor system of 
training evaluation and use of evaluation results. It is the reason for resource wastages. For achieving desired level of performance, planning, implementation and evaluation of the training should be effective indicator of training ineffectiveness was used in this study and a framework was developed for measuring training effectiveness and diagnoses problems at various stages of training ${ }^{10}$ conducted an analysis of four Collaborative Reproductive Health (CRH) projects in Thailand to investigate the level of project management knowledge and implementation utilized within $\mathrm{CRH}$ project. The study also identified the contribution of project management to sustainable outcomes. The study used Project Management Body of Knowledge (PMBOK) as a benchmark. The findings of the study showed that knowledge utilized in the projects was not in line with the practice used on PMBOK guide. The utilization of project management knowledge in some areas affected $\mathrm{CRH}$ project implementation. So improved project management knowledge contributes to improved project implementation. The authors also recommended that Prioritization of Project Management Knowledge Area (PMKA) will contribute to sustainable outcome ${ }^{11}$ conducted a 15 months national research study comprising consultations with 195 stakeholders and five surveys involving 718 managers trainers \& participants to measure the effectiveness of Cross Cultural Training (CCT) in the Australian Public and Community sectors. The study revealed statistically significant evidence that CCT provides direct benefit of the employees, their organization and clients. ${ }^{12}$

\section{Conclusion}

The objective of this review was to identify the trend of the assessment of the training effectiveness to achieve the desired goal of training. Articles on assessment of training effectiveness from 2006 to 2015 were reviewed to determine the factors which measure the training effectiveness. It is found from the literature review that a comprehensive framework to measure training effectiveness should be developed because learning gains cannot be achieved without proper evaluation. Problem diagnosis is a must in every stages of the training cycle. Views of the stakeholders should be incorporated to design an effective training. It is recommended that reaction, learning, behavior and result should be evaluated to achieve the goal of training. Updated tools and techniques should be applied to implement as well as evaluate the training. Training is a continuous process. The theme of training effectiveness can be further researched to find out the appropriate way of training accomplishment which benefits the stakeholders.

\section{Acknowledgments}

None.

\section{Conflict of interest}

The author declares there is no conflict of interest.

\section{References}

1. Shariff S, Jahan Z, Jamil N. Assessment of Project Management Skills and Learning Outcomes in Students' Project. Procedia Social and Behavioral Sciences. 2013;90:745-754.

2. Hornyak M, Lawlon B. Assessing Project Management as an academic Learning outcome (ALO). Developments in Business Simulation and Experiential Learning. 2013;40:344-353.

3. Begum N, Biswas T. Post Training Utilization of AARDO Courses in Bangladesh; 2010.

4. Arasanmi C, Wang W, Singh H. Motivational Determinants of Training Utilization in Enterprise Systems. Proceedings of the Eighteenth Americas Conference on Information systems, Seattle, Wastrington, 2012. p. 9-12.

5. Zou P. Designing Effective Assessment in Postgraduate construction Project management studies. Jounal for Education in the built environment. 2008;3(1)80-94.

6. Purcell B. Use of formative classroom assessment techniques in a project management course. Jounal of Case Studies in Accreditation and Assessment. 2014;1:1-6.

7. Albadri F, Abdallah S. ERP Training and Evaluation: ERP life-Cycle Approach to End-Users' characterization and competency Building in the Context of an Oil \& Gas company. Journal of IBIMA Business Review. 2010;3.

8. Warui K. Impact of Training on Project Management Effectiveness among Secondary School Principals in Kenya. Educational Research International. 2013;2(3).

9. Rehman A, Khan A, Khan R. Measuring Training Effectiveness: A Case Study of Public Sector Project Management in Pakistan. Journal of diversity Management. 2011;6(1):39-48.

10. Dumark J, Banoudi B, Pullen S. A Study of Project management knowledge and sustainable outcomes in Thailand's reproductive health projects. Organizational Project Management. $2015 ; 2$ (1):1-14.

11. Bean R. The effectiveness of Cross-Cultural Training in the Australian Context; 2006.

12. Nijhuis S. Project management tuition on training. Can we assess the added value of them?. Procedia Social and Behavioral Sciences. 2015;194:146-154. 